
\title{
25 Research Suare \\ Can the DREEM scale be adapted to the medical simulation environment?
}

Izabela Mamcarz

Uniwersytet Medyczny w Lublinie

\section{Anna Torres}

Uniwersytet Medyczny w Lublinie

Piotr Mamcarz ( $\nabla$ pmamcarz@kul.pl )

Katolicki Uniwersytet Lubelski Jana Pawla II Wydzial Nauk Spolecznych https://orcid.org/0000-00016307-6326

\section{Kamil Torres}

Warszawski Uniwersytet Medyczny

\section{Research article}

Keywords: medical simulation, educational environment, DREEM scale, medical simulation environment, adaptation

Posted Date: December 12th, 2019

DOI: https://doi.org/10.21203/rs.2.18689/v1

License: (c) (i) This work is licensed under a Creative Commons Attribution 4.0 International License. Read Full License 


\section{Abstract}

\section{Background}

The environment of medical simulation is a specific educational environment for teaching medicine. Medical universities are obliged to ensure appropriate conditions for conducting classes in medical simulation. In order to improve the quality of courses in simulation, it is necessary to get to know the educational environment and the medical simulation environment. It will be possible thanks to appropriately selected methods, which include important variables shaping these environments.

Methods

Among 312 medical students who had classes in medical simulation, the DREEM method (Roff et al.) and the QuESST method (Mamcarz et al.) were applied.

Results

The process of adapting the DREEM tool to Polish conditions and the construction stages of the QuESST tool were presented. The overall results of the QuESST and DREEM questionnaires correlated significantly. Also the overall result of QuESST correlated significantly with the results of individual DREEM scales.

Conclusions

The presented tools may be helpful in determining the educational conditions and conditions of medical simulation as a specific educational environment for teaching and learning medicine.

\section{Background}

Developing an educational environment is essential for the overall learning process. It is increasingly recognised as essential to meet the criteria for a high level of medical education (1). The way a student perceives the educational environment in which he or she finds himself or herself may translate into behaviour in the future (2).

The use of simulation methods in the teaching of medicine is connected with the creation of a specific educational environment. The teaching process itself should meet specific requirements, including the provision of an appropriate learning environment to optimise the learning process (1). This applies to simulation methods, which are designed to create an environment as close as possible to the realities of the clinic. The perception of the educational environment by medical students and teachers is an important variable, which may shape to a large extent the effectiveness of the use of simulation methods (3). 
The Educational Environment Assessment Method (DREEM) was designed by Roff and co-authors (4) as a tool to study the educational environment. It is not sensitive to cultural differences and can be widely used in medical and health care institutions.

Despite the undeniable advantages of the DREEM tool, it includes general aspects of the educational environment. In the ongoing research project, it was also important to consider the aspects of the simulation environment as a specific educational environment.

The simulation environment provides students with an opportunity to implement previously planned scenarios, perform specific procedures in safe and more predictable conditions. In addition to the many advantages associated with the use of medical simulation in medical teaching, it should undoubtedly be emphasized that the simulation environment is a reflection of the environmental conditions prevailing in the real world, for example in the clinic. The conditions created by a simulation are an essential factor shaping and giving meaning to the whole educational process of the simulation. The potential of individual or team training in simulated conditions lies in the translation of proven educational methods into simulated conditions. These methods include reflexive learning and debriefing (5).

The medical simulation environment is designed to achieve specific goals in medical education. These objectives include enabling the student to have direct contact with the patient, acquire specific clinical skills, perform diagnostic procedures with the possibility of exercising and repeating procedures. The use of medical simulation in education improves the quality of this education, translating, among other things, into an increase in the level of students' knowledge, strengthening their internal motivation or belief in self-efficacy (6).

The use of the medical simulation environment in medical education is therefore a huge potential for a more complete implementation of the assumed educational goals and enabling the acquisition of specific clinical skills, which will then be used in the professional life of students.

In order to take into account the conditions of the simulation environment as specific conditions of the students' learning process, a proprietary Questionnaire for Evaluation of Satisfaction of Simulation Training (QuESST) method was designed. It enables to characterize the simulation environment as specific conditions for the acquisition of knowledge and skills. It describes, among others, such aspects of the learning process in the simulation environment as: premises conditions, students' attitude towards classes in simulation conditions, students' opinions on the strengths and weaknesses of the simulation. The DREEM tool described above is very attractive psychometrically, but does not refer to specific simulation conditions as teaching conditions. This tool was the main point of reference for the construction of a new tool, which focuses on educational conditions with particular emphasis on the conditions of medical simulation. Thanks to this work, it is possible to both generalize the aspects related to educational conditions, as well as to characterize specific aspects of the simulation conditions as an educational environment. The activities undertaken are the initial stage of work on the construction of the QuESST tool. It would be worthwhile, however, to undertake further actions aimed at strengthening the psychometric values of the tool. 


\section{Methods}

\section{ADAPTATION OF THE DREEM SCALE}

The DREEM questionnaire, constructed by Roff and co-authors (4), consists of 50 theorems referring thematically to the educational environment, grouped in 5 subscale:

I. Students' perception of the learning process

II. Students' perception of teachers

III. Self-perception in the academic environment

IV. The perception of the atmosphere by students

V. Self-perception in society

The method examining the educational environment has achieved high reliability, accuracy and is used to examine medical students, nurses, dentists and other medical professions. It allows to conduct diagnostic analyses at the pre-diploma level in medical schools and other institutions connected with health education. It can be used to compare medical schools in terms of the existing conditions of the educational environment, as well as for individual elements of courses (4).

The stages of the adaptation process of the DREEM scale are presented below:

1. Obtaining the consent of the authors of the DREEM method to carry out the adaptation process;

2. Obtaining the original versions of the questionnaire together with the information necessary to make statistical calculations;

3. Translation of the method from English into Polish by two independent translators;

4. Summary of the two translations in the form of a table;

5. Evaluation of two translations by 10 competent English-speaking referees at the minimum level. $\mathrm{C} 1$. The evaluation criterion was included in the question - Which translation is closer in meaning to the original?

6. A summary of the assessments of the competent judges;

7. Selection of the translation for each claim individually according to the criterion - frequency of product. The correct translation was the one that was chosen more frequently by the judges;

8. Creating a draft version of the DREEM method in the Polish language, based on the assessment of translations by competent judges. Linguistic and stylistic proofreading while maintaining accurate translation of statements;

9. Retranslation of methods from Polish into English by an independent translator;

10. Comparison by a competent judge fluent in English of two English versions of the methods: the original version with the return translation from Polish. The assessment was made by determining on a scale of 0-1 whether the translation of the method is consistent with the original version; 
11. Summary of the adaptation process by taking into account to the Polish version of the method those statements which on the 0-1 scale achieved the value of 1 and improving the meaning of statements which achieved the value of 0 ;

12. Graphic and content-related development of DREEM method in terms of maintaining the principle of facade equivalence of questionnaires;

13. Conducting pilot studies to determine the psychometric properties of the adapted DREEM scales. The pilot study involved 50 people tested twice (test and retest) - the second study was conducted after a one-month break. The results of the conducted analyses are presented in Table 1.

The value of the Alfa Cronbach coefficient for the original DREEM questionnaire is $a=0,91$ (46), while the value of the Alfa Cronbach coefficient for the adapted DREEM questionnaire is $a=0,95$, which indicates the good reliability of the version of the adapted method. The value of the t-test for the DREEM questionnaire shows a lack of materiality, which means that the result is internally relevant (Table 1).

The above psychometric values confirm the adaptation of the questionnaire according to the methodology.

\section{CONSTRUCTION OF THE QUESTIONNAIRE FOR EVALUATION OF SATISFACTION OF SIMULATION TRAINING (QUESST)}

The QuESST scale consists of 20 statements describing the simulation environment as a learning environment for students. Respondents answer on a 5-degree Likert scale, where the extreme values of this scale correspond to the theorems - I completely agree and completely disagree.

In order to determine the reliability of the constructed QuESST method, the reliability coefficient of Alfa Cronbach was calculated. The reliability of the scale for 20 items was $a=0.865$. In order to determine the internal structure, the loads of particular items were analysed by using Component Analysis. It was assumed that the items would be included in the structure of the method if the value of the load was above or equal to 0.30 (Table 2). The four claims that were removed from the method did not meet this criterion. Therefore, the method was re-examined for reliability. The Alpha Cronbach value after deletion of the four entries is $a=0,91$.

The paper also presents the mutual correlations between the overall result of the QuESST scale and the overall result and individual scales results of the DREEM tool.

Table 3 shows the correlations between the overall score of the QuESST and the overall score and the individual scales of the DREEM tool.

The obtained results indicate that the obtained correlations are at the level of significance equal to $\mathrm{p} \leq 0.001$. 
The overall score of the QuESST method correlated moderately with the Perception of teachers scale DREEM ( $r=0.433)$, Academic self-perception - DREEM ( $r=0.420)$, Social self-perception - DREEM $(r=0.443)$. The overall score of QuESST correlated strongly with the following scales: overall score of the DREEM method ( $r=0.559)$, Perception of the learning process - DREEM $(r=0.544)$ and Perception of the atmosphere - DREEM $(r=0.544)$.

\section{Disscussion}

Organization of the educational environment is an important factor influencing the level of realization of the assumed educational goals. Medical simulation is a special kind of educational environment. Due to legislative changes concerning the standards of education in medical faculties, it has become a popular and necessary method of effective implementation of the contents of the curriculum. Simulated environment, defined in the standard of education as simulated clinical conditions, optimally used, brings with it a great educational potential. The full use of the resources of this type of environment consists of, among others, the attitude of the student and teacher to work with simulation methods. In this paper, therefore, an attempt has been made to examine the perspectives of students and academic teachers in the context of the conditions associated with the implementation of the curriculum using a simulated environment (7).

Medical simulation is certainly a specific educational environment, which should meet specific requirements in order for the educational activities to produce the expected results. Researchers attempt to define the role of simulation in medical education $(8,9)$. Reynolds et al. (2008) present research aimed at assessing the impact of medical simulation-based teaching on students' knowledge and satisfaction with the teaching process. They conducted research in connection with the course of Obstetrics and Gynaecology. The results of these studies presented by them indicate that classes based on medical simulation increase students' satisfaction with the teaching process (10).

Undoubtedly, a strong point of organizing the learning process in a simulation environment is the possibility of implementing specific content while maintaining patient safety. The student has the ability to undertake activities and procedures in a repetitive manner, without exposing the potential patient to risk. At the same time, the simulation environment is a reflection of the conditions that will most likely be found in the work environment in the future. This translates into the process of using the acquired knowledge and skills. Healthcare professions require not only technical skills or knowledge of specific medical procedures. It also requires future physicians and nurses to have non-technical skills, make decisions, work in a team, communicate with patients of different ages and needs (11). Classes conducted by students in simulated conditions provide an opportunity to practice and acquire these skills which are necessary for future work.

Despite the benefits of using medical simulation in teaching, it also has its limitations. Bokken et al. (2008) attempted to identify the strengths and weaknesses of the real and simulated patient in pre- 
diploma education. Their research shows that each type of patient has its own advantages and disadvantages from the perspective of teachers, students and patients themselves. At the same time, researchers stress the need to deepen the knowledge on the role of patients in medical education (12).

Hssain et al. (2012) stresses the need to know how to use simulation techniques in order to ensure their proper use in the teaching process and the need to use medical simulation at an appropriate stage of the educational process. Researchers emphasize that the effectiveness of simulation methods is influenced by their combined use with traditional methods. Therefore, this issue should be consciously planned by educators. Other limitations on the use of simulated methods include the high costs associated with the use of simulated methods in the educational process (13). Not every unit that educates students in medical faculties has the financial and accommodation capacity to use the method of medical simulation in teaching.

The Questionnaire for Evaluation of Satisfaction of Simulation Training Student in Simulation Questionnaire (QuESST) is a summary of aspects related to simulation experience and organization of the simulation environment as an educational environment. Standards for this method were calculated based on quartiles. The questionnaire takes into account, among others, the content related to the attitude, involvement and preparation of academic teachers for classes, organization of classes and the level of realism of classes. Students may also assess how engaging the classes are for them in simulated conditions, to what extent they give them the opportunity to learn practical skills and to what extent they improve students' communication skills. The QuESST questionnaire therefore takes into account a wide spectrum of the organization of simulation classes, as well as the content related to the opinion on academic teacher and self-evaluation of students in the context of simulation classes.

Very interesting correlations were obtained by using a correlation analysis between the overall result of the QuESST questionnaire and the overall result and the individual scales of the DREEM questionnaire. Both the overall results of the QuESST and DREEM tools, as well as the overall result of QuESST and the results of individual DREEM scales correlated significantly with each other statistically. These correlations mean that the increase in the overall score of the QuESST questionnaire was linked to the increase in the overall score and the results of the individual scales of the DREEM questionnaire. The assessment of the educational environment was therefore related to the assessment of the simulation conditions by the students. The assessment of the educational environment could be based on the students' satisfaction with the experience with simulation. The QuESST method seemed to confirm this relationship in a good way. High correlations between the QuESST authoring tool and the existing DREEM tool may suggest a high psychometric value of QuESST.

The described educational environment seems to be very important. It is a kind of basis for the development of conditions in which learning will be organized using simulation methods $(14,1,15)$. A well-organized general educational environment can be the first step in the further planning of education in simulated conditions. 
The simulation environment requires appropriate preparation of teaching conditions, appropriate embedding in the curriculum and organization from the administrative point of view, high level of content, appropriate attitude of persons leading to the content, ability to interact with students, ability to design scenarios and course of classes (16). Even a small inconvenience on the part of technical equipment may disturb the course of classes and their realism.

Proper design and construction of the educational environment seems to be important from the perspective of optimizing the learning process. This is particularly important from the perspective of the teaching process in medical faculties, where students often have to face real-life situations in a hospital or clinic. Adaptation of the DREEM tool seems to be important for the proper assessment of the educational environment. Additionally, in order to specifically capture the conditions of the simulation environment as an educational environment, it seemed necessary to construct an appropriate tool. The QuESST tool seems to capture well the aspects related to the educational process in the simulation. The proper design of the educational process allows for the realization of the content of the teaching process and the achievement of the assumed educational goals. It is also needed to undertake further work on strengthening the construction and psychometric values of the QuESST tool.

\section{Conclusions}

The presented work shows the DREEM adaptation procedure for polish conditions and the construction of the QuESST tools that embraces the conditions of medical simulation as a specific educational environment. The DREEM tool is a well standardized method, and the actions undertaken in this work were aimed at testing the method in the simulation environment in Poland. Poland is a country of 38 million people, where many doctors migrate to other countries to work there. In Poland, many doctors and specialists are educated in medical education at a high level. In addition, steps have also been taken to change medical education. These changes provide an opportunity to strengthen and improve educational conditions. The above conditions of the educational process at medical faculties in Poland require the simultaneous development and improvement of both conceptual and practical issues related to the teaching of medicine. Many new procedures are needed to be supplemented in different medical education areas (17).

Since 2013, Poland has introduced a process of medical education that includes medical simulation, educational profile is largely focused on practical aspects, the standardization of the educational process is taken into account. Hence, our goal was to construct tools that would cover the aspects related to the simulation environment, with particular emphasis on medical simulation.

\section{Limitations And Further Directions}

In this article we described a stage of initial work on adaptation and construction of tools. In the next stages it will be necessary to introduce the adapted DREEM scale into a wider simulation environment, taking into account several medical simulation centers in Poland. 
Due to the fact that medical simulation was included in the process of medical education in Poland, it was necessary to make an attempt at constructing a tool for testing the simulation environment as a specific educational environment. Despite the fact that the DREEM tool is well standardized, is used in many countries and appears in the literature, it does not directly address specific simulation conditions. This tool clearly refers to 5 dimensions related to the educational environment, but does not refer to specific simulation conditions that make up the process of medical education in Poland. However, DREEM questionnaire was the basis for us to undertake work related to the construction of a specific QuESST tool. Thanks to the reference to the DREEM questionnaire, this QuESST has a good external relevance and seems to meet the needs that emerged in response to legislative changes in medical education in Poland.

\section{Abbreviations}

DREEM The Educational Environment Assessment Method

QuESST Questionnaire for Evaluation of Satisfaction of Simulation Training

\section{Declarations}

\section{ETHICS APPROVAL AND CONSENT TO PARTICIPATE}

This study was approved by the Medical University in Lublin

Respondents were informed that participation in the study is considered as granting consent to the study Written informed consent was obtained from the patient for the publication of this case report.

\section{CONSENT FOR PUBLICATION}

Not applicable

\section{AVAILABILITY OF DATA AND MATERIALS}

The datasets during and/or analysed during the current study available from the corresponding author on reasonable request.

\section{COMPETING INTERESTS}

The authors declare that they have no competing interests

\section{FUNDING}

The authors received no financial support for the research, authorship, and/or publication of this article.

\section{AUTHORS' CONTRIBUTIONS}


KT have made substantial contributions to the conception and designing the work; PM contributed to the analysis of the data; IM contributed in the interpretation of the data and preparation the introduction; AT substantively revised the work

\section{ACKNOWLEDGEMENTS}

Not Applicable

\section{References}

1. Schönrock-Adema J, Bouwkamp-Timmer T, van Hell EA, Cohen-Schotanus J. Key elements in assessing the educational environment: where is the theory? Advances in Health Sciences Education. 2012;17(5):727-742.

2. Genn JM. AMEE Medical Education Guide No. 23 (Part 1): Curriculum, environment, climate, quality and change in medical education-a unifying perspective. Medical Teacher. 2001a;23(4):337-344.

3. Sadideen H, Hamaoui K, Saadeddin M, Kneebone R. Simulators and the simulation environment: Getting the balance right in simulation-based surgical education. International Journal of Surgery. 2012;10(9):458-462.

4. Roff S, McAleer S, Harden RM, Al-Qahtani M, Ahmed AU, Deza H, Groenen G, Primparyon P. Development and validation of the Dundee Ready Education Environment Measure (DREEM). Med Teach. 1997;19(4):295-299.

5. Dunn W, Murphy JG. Simulation. Chest. 2008;133(1):6-9.

6. Makransky G, Bonde MT, Wulff JSG, Wandall J, Hood M, Creed PA, i in. Simulation based virtual learning environment in medical genetics counseling: an example of bridging the gap between theory and practice in medical education. BMC Medical Education.2016;16(1).

7. Chakravarthy B, Haar E, Bhat S, McCoy C, Denmark TK, Lotfipour S. Simulation in Medical School Education: Review for Emergency Medicine. Western Journal of Emergency Medicine. 2011;12(4):461-466.

8. Issenberg SB, McGaghie WC, Petrusa ER, Lee Gordon D, Scalese RJ. Features and uses of high-fidelity medical simulations that lead to effective learning: a BEME systematic review. Medical Teacher.2005;27(1):10-28.

9. Bagnasco A, Pagnucci N, Tolotti A, Rosa F, Torre G, Sasso L. The role of simulation in developing communication and gestural skills in medical students. BMC Medical Education. 2014;14(1).

10. Reynolds A, Ayres-de-Campos D, Bastos L, van Meurs WL, Bernardes J. Impact of Labor and Delivery Simulation Classes in Undergraduate Medical Learning. Medical Education Online. 2008;13(1): 4483. 
11. Kang I, Foster Page LA, Anderson VR, Thomson WM, Broadbent JM. Changes in students' perceptions of their dental education environment. Eur J Dent Educ. 2015;19:122-130.

12. Bokken L, Rethans JJ, Scherpbier AJJA, van der Vleuten CPM. Strengths and Weaknesses of Simulated and Real Patients in the Teaching of Skills to Medical Students: A Review. Simulation in Healthcare: The Journal of the Society for Simulation in Healthcare.2008;3(3):161-169.

13. Hssain I. Benefits \& limitations of medical simulation in emergency medicine. Mediterranean Journal of Emergency Medicine.2012;9-14.

14. Bassaw B, Roff S, McAleer S, Roopnarinesingh S, De Lisle J, Teelucksingh S, Gopaul S. Students' perspectives on the educational environment, Faculty of Medical Sciences, Trinidad. Medical Teacher. 2003;25(5):522-526.

15. Arney D, et al. Simulation of medical device network performance and requirements for an integrated clinical environment. Biomedical instrumentation \& technology.2012;46.4:308-315

16. Datta R, Upadhyay K, Jaideep C. Simulation and its role in medical education.Medical journal, Armed Forces India.2012;68(2):167-172.

17. Janczukowicz, J. Medical education in Poland. Medical Teacher, 2013;35(7), 537-543. doi:10.3109/0142159x.2013.789133

\section{Tables}

Table 1. Internal accuracy of the DREEM scale. Test-retest analysis

\begin{tabular}{|l|l|l|l|l|l|l|}
\hline & \multicolumn{3}{|l|}{ Test } & \multicolumn{2}{l|}{ Retest } & \multicolumn{2}{l|}{ Test t Studenta } \\
\hline & $\mathbf{M}$ & $\mathbf{s d}$ & $\mathbf{M}$ & $\mathbf{s d}$ & $\mathbf{t}$ & $\mathbf{p}$ \\
\hline DREEM & 130,54 & 27,11 & 133,32 & 25,30 &,- 584 &, 562 \\
\hline
\end{tabular}

Table 2. Items factoral load 


\begin{tabular}{|l|l|l|l|}
\hline \multicolumn{4}{|l|}{ Component Analysis } \\
\hline Item & Compound & Item & Compound \\
\hline 1 &, 800 & 11 &, 537 \\
\hline 2 &, 694 & 12 &, 520 \\
\hline 3 &, 085 & 13 &, 754 \\
\hline 4 &, 662 & 14 &, 276 \\
\hline 5 &, 783 & 15 &, 377 \\
\hline 6 &, 717 & 16 &, 714 \\
\hline 7 &, 573 & 17 &, 656 \\
\hline 8 &,- 217 & 18 &,- 343 \\
\hline 9 &, 744 & 19 &, 647 \\
\hline 10 &, 665 & 20 &, 804 \\
\hline
\end{tabular}

Table 3. Correlations between the overall result of the QuESST and the overall result and individual scales results of the DREEM tool

\begin{tabular}{|l|c|}
\hline & QuESST GS \\
\hline DREEM GS &, $559^{* * *}$ \\
\hline Perception of the learning process &, $544^{* * *}$ \\
\hline Perception of teachers &, $433^{* * *}$ \\
\hline Self-perception in the academic environment &, $420^{* * *}$ \\
\hline Perception of the atmosphere &, $544^{* * *}$ \\
\hline Self-perception in society &, $443^{* * *}$ \\
\hline
\end{tabular}

$$
\text { *PE 0.05; ** P } £ 0.01 ; * * * P £ 0.001
$$

